\title{
Familial Nonmedullary Thyroid Gland Carcinoma
}

National Cancer Institute

\section{Source}

National Cancer Institute. Familial Nonmedullary Thyroid Gland Carcinoma. NCI

Thesaurus. Code C118829.

A papillary or follicular thyroid gland carcinoma with a genetic component that develops

within the same family. Current studies suggest that it is inherited in an autosomal

dominant pattern. It is often multifocal and bilateral and usually affects younger patients. 